\title{
Reflexões sobre o hibridismo vocal em performance
}

\section{Reflections on vocal hybridity in performance}

Cristiane dos Santos Souza 


\section{Resumo}

O presente trabalho analisa as possibilidades expressivas da voz cênica na contemporaneidade. Para refletir sobre a relação entre corpo, voz, performance e cultura, adotou-se como referenciais teóricos os seguintes trabalhos: os estudos sobre o hibridismo cultural a partir de Peter Burke; a ideia de performance vocal por Paul Zumthor; o relato de experiência do Alfabeto do Corpo sistematizado por Zygmunt Molik e o conceito de paisagem sonora elaborado por Raymond Murray Schafer. Além do debate teórico, o texto apresenta dois relatos de experiência prática que transitam entre o fazer artístico e a docência, ambos relacionados à voz.

Palavras-chave: Voz; hibridismo cultural; experiências.

\section{Abstract}

This article is intended to analyze the expressing possibilities of scenic voice in contemporaneity. In order to examine the relation between body, voice, performance and culture, it will be considered the following studies on cultural hybridity: the works of Peter Burke; the idea of vocal performance as conceived by Paul Zumthor; The Alphabet of the Body, elaborated by Zygmunt Molik and, finally, Raymond Murray Schafer's concept of soundscape. Besides the theoretical analysis, this article shall present two reports on practical experiences concerning the artistic performance and teaching related to the voice.

Keywords: Voice; cultural hibridity; experiences.

ISSN: 1414.5731

${ }^{1}$ Universidade Federal do Paraná. Profa Dra. Curitiba (PR). cristiane.titi.souza@gmail.com 
O presente trabalho pretende refletir sobre as possibilidades expressivas da voz cênica na contemporaneidade. Antes de abordar o tema, é importante lembrar que a reconhecida contribuição proveniente de estudos científicos do campo da fonoaudiologia, focados na relação anatômica e fisiológica da saúde vocal, não se sobrepõe a outras abordagens, dentre as quais a reflexão em torno da pesquisa vocal cênica. A abordagem dessa área específica requer adentrar no campo do hibridismo cultural, investigar novas possibilidades de projeção vocal e de produção de sonorizações construídas no constante diálogo com estudos práticos e teóricos vinculados ao Teatro, ao Canto e à Poesia Sonora.

Essas áreas buscam, com base em técnicas de expressividade artística, desenvolver uma presença e uma força vocal cênica apta não só a potencializar a palavra falada ou cantada, como também a comunicar e expressar intenções para além do significado da palavra, do que é pronunciado. Em sentido lato, compreende-se a voz como som em intercâmbio intrínseco com o corpo e que, ao ser deslocada de seu uso naturalizado no cotidiano, pode ser tema de análise que leve em conta a memória sonora e percepções mais aguçadas. Tal análise permite contribuir para a construção e expansão de outros significados culturais em torno da performance vocal, que se constituem - por que não dizer? - matéria artística. Sendo assim, ressalta-se que o presente trabalho pretende discutir possibilidades vocais híbridas distanciadas do uso da voz cotidiana, ou seja, para além do aspecto mecânico e automatizado da comunicação diária.

A partir dessas questões, foram mobilizadas algumas teorias entendidas como relevantes para o debate aqui em tela. Da diversidade teórica abrangendo a relação corpo, voz, performance e cultura, adotou-se como referenciais os estudos pautados no hibridismo cultural desenvolvido pelo historiador inglês Peter Burke; a ideia de performance vocal a partir de outro historiador, o francês Paul Zumthor; o estudo da metodologia caracterizada pelo chamado Alfabeto do Corpo, criada pelo ator polonês Zygmunt Molik e, o conceito de paisagem sonora elaborado pelo músico canadense Raymond Murray Schafer. Essas teorias e seus respectivos autores, entretanto, não esgotam as discussões conceituais travadas ao longo deste artigo, que pretende, conforme sinalizado no título, refletir acerca do hibridismo vocal em performance.

Procurando sistematizar o debate, o texto foi organizado em três partes: na primeira, intitulada Do hibridismo cultural às expressões híbridas da voz performática, priorizou-se a discussão sobre os estudos supracitados procurando examinar alguns conceitos neles mobilizados cuja compreensão, de uma maneira ou de outra, seja relevante para o presente estudo. Na sequência, no tópico Para além do cotidiano vocal: o Alfabeto do Corpo como uma possibilidade de conexão entre corpo e voz, refletiu-se sobre uma possível hibridação entre a metodologia proposta por Zygmunt Molik em seu Alfabeto do Corpo e a ideia de performance vocal. Por fim, no último tópico Entre a experimentação acadêmica e o palco na redescoberta da voz, o texto apresentou dois relatos de experiências profissionais relacionadas à voz. 


\section{Do hibridismo cultural às expressões híbridas da voz performática}

Conforme já sublinhado por Burke, a tendência da atualidade é viver o hibridismo. Para esse autor,

A preocupação com este assunto é natural em um período como o nosso, marcado por encontros culturais cada vez mais frequentes e intensos. A globalização cultural envolve hibridação. Por mais que reajamos a ela, não conseguimos nos livrar da tendência global para a mistura e a hibridização (2003, p. 2).

Teóricos do hibridismo cultural citados por Burke apresentam uma identidade construída pelo que podemos chamar de contaminações e trocas culturais. ${ }^{2}$ Ainda que esse autor, ao escrever o livro Hibridismo Cultural, não tenha focado sua atenção nas questões vocais, sua análise em torno do que chamou de variedades de objetos, especificamente no tópico sobre práticas híbridas, nos permite adentrar em uma reflexão em torno de hibridizações impressas à voz. Ao refletir acerca da linguagem, Burke aborda a Europa dos séculos XVI e XVII, enfatizando que, nesse período,

[...] aumentou o grau de misturas das línguas europeias entre si porque os contatos entre elas foram ficando cada vez mais numerosos. Por um lado, aumentou a migração dentro da própria Europa. Por outro, o gradual declínio do latim e o crescente uso de línguas vernáculas em textos impressos tornou mais necessário do que antes que os europeus aprendessem uns as línguas dos outros (2003, p. 34).

Temos também no Brasil um caso exemplar de hibridismo de linguagens, que já nasce no período de colonização, quando indígenas, africanos, portugueses e espanhóis passam a partilhar o mesmo cenário cultural. Segundo Luiz Tatit, a "sonoridade desse período identifica uma certa fusão das práticas nativas com a atividade doutrinária dos jesuítas" (2004, p. 19). Tatit também destaca a participação portuguesa nessa fusão, com os "hinos católicos de celebração e catequese, mais melódicos que rítmicos, ressoando o canto gregoriano do medievo europeu" (Ibidem, p. 20). Pouco depois, graças à chegada dos africanos, "a percussão e a dança foram gradativamente reforçadas pela 'dicção negra'" (Ibidem, p. 21), o que agregou um novo elemento à variedade do hibridismo brasileiro.

Desse encontro entre as mais diferentes línguas faladas emergem características vocais que, por sua vez, expressam não só a cultura a que um determinado grupo pertence como também revelam diferentes trocas culturais a que o grupo está constantemente sujeito. No mais, a voz revela, muitas vezes, estados de emoção. Sotaques, cacoetes, intensidade, velocidade, altura e articulação da fala são exemplos de elementos constituidores da expressão vocal que, por sua vez,

\footnotetext{
2 Teóricos citados por Burke na obra Hibridismo Cultural: Homi Bhabha (nasceu em 1949), indiano que foi professor na Inglaterra e hoje atua nos Estados Unidos; Stuart Hall (1932-2014), nascido na Jamaica, de ascendência mista, viveu a maior parte da sua vida na Inglaterra; len Ang (nasceu em 1954), chinesa, nascida na Indonésia
}

e educada na Europa, atualmente trabalha na Austrália; Nestor Canclini (nasceu em 1939), que cresceu na Argentina e vive no México; Edward Said (1935-2003), palestino que cresceu no Egito, e foi professor nos Estados Unidos. 
manifestam processos de encontros culturais que com o passar do tempo tendem a se intensificar. Em síntese, a linguagem vocal, assim como também "a música, [...] oferece muitos exemplos notáveis de hibridação". (Burke, 2003, p. 32).

No que diz respeito às tendências teatrais, performances e poesias sonoras mais recentes, observamos que voz, texto e ruídos se misturam na ideia de paisagem sonora. Especificamente na cena teatral pós-dramática, encontramos o que Lehmann ${ }^{3}$ chamou de "peça-paisagem", na qual "texto, voz e ruído se misturam na ideia de paisagem sonora". (2007, p. 254).

A ideia de paisagem sonora (soundscape) foi inicialmente pensada por Raymond Murray Schafer. O autor nos convida a prestar atenção nos sons do ambiente e do espaço, em um exercício contínuo de captação e registro das sensações provocadas pelos sons. De acordo com ele, o estudo da paisagem sonora permite o contato com o processo híbrido e dinâmico de uma sociedade em transformação, na qual os avanços tecnológicos interferem diretamente no tipo de ruído produzido. Schafer lança uma questão em sua obra A Afinação do Mundo: "Qual é a relação entre os homens e os sons de seu ambiente e o que acontece quando esses sons se modificam?" (2011, p. 18).

O autor parece querer enfatizar que os sons, aparentemente naturais, são gerados de maneira dinâmica e recorrente, e sua variedade reflete as constantes transformações sociais e culturais em sua relação de interdependência com as pessoas. E que estas, por sua vez, poderiam ampliar criticamente sua percepção sonora para além dos automatismos sensoriais cotidianos. Nesta direção,

Aliada à consciência pedagógica do som, Schafer emprega a poesia sonora para uma consciência do mundo, levando o ser humano a pensar numa política sonora. Sua proposta básica consiste em fazer com que as pessoas se desvinculem da automação sonora cotidiana e passem a apreciar o mundo sonoro onde vivem (Minarelli, 2014, p. 30).

Voz, por sua vez, está diretamente ligada ao som, ou seja, a diversidade sonora contribui para a diversidade vocal e vice-versa. À palavra ligam-se sons que possibilitam desdobramentos da voz que, embora esteja associada ao sujeito enunciador, revela imbricações culturais construídas na relação com outros sujeitos e com o ambiente. Sendo assim, no caso da voz cênica, seu uso passa por uma relação de pesquisa consciente na qual o ouvir, o observar, o experimentar possibilidades vocais são aspectos importantes para se chegar a uma qualidade vocal cênica. Isso permite que a singularidade em intercâmbio com a coletividade produza no enunciador um jeito de falar culturalmente construído, e que, no caso da voz cênica, pode ser intencionalmente criado culminando na chamada voz performática.

A voz performática se beneficia de artifícios diferenciados e muitas vezes não experimentados no uso cotidiano. Sua expressão pressupõe comunicação 
com um público variável. Essa "voz dilatada", para empregarmos uma expressão inspirada nos estudos de Eugenio Barba, precisa ser construída em e com presença cênica. Diferente da voz cotidiana, a voz em cena deve explorar as possibilidades sonoras de maneira consciente tendendo a provocar novas percepções no espectador de modo que este possa criar imagens e também abstrair dos sons um significado.

Sobre essa ideia de voz cênica, é pertinente evocar os estudos de Paul Zumthor a respeito da tríade performática, que envolve a relação entre intérprete, texto, ouvinte. O autor, a partir do interesse pela oralidade na Idade Média, contribuiu para a reflexão em torno do texto poético como performance. Zumthor não se limita aos estudos das oralidades nesse período, mas reflete também sobre o uso da voz na sociedade de consumo típica da atualidade. Para ele

A civilização dita tecnológica ou pós-industrial está em vias de sufocar em todo o mundo o que subsiste das outras culturas e de nos impor o modelo de uma brutal sociedade de consumo. (...) não se pode duvidar de que estejamos hoje no limiar de uma nova era da oralidade, sem dúvida muito diferente do que foi a oralidade tradicional; no seio de uma cultura na qual a voz, em sua qualidade de emanação do corpo, é um motor essencial da energia coletiva (2007, p. 63).

A voz se afigura, contudo, uma possibilidade de exaltação da diversidade e de resistência a um impulso cultural que tende à homogeneização. Sendo diretamente ligada à voz, a performance vocal estaria, nesta medida, associada àquela resistência, na medida em que procuraria desenvolver maneiras não habituais de expressão sonora, que busquem romper com o contexto espacial e temporal em que aquela performance tem lugar.

Para Enzo Minarelli ao comentar a teoria zumthoriana,

[...] A comunicação não está num vazio temporal nem espacial: encontra-se num presente que sofre interferência de um passado, ao passo que projeta o futuro. Todo ato de comunicação é espacial, envolve lugar, objeto, códigos, canais e pessoas. A poesia oral, pelo contato direto com seu receptor e pela recorrência direta à voz; é uma expressão cujo evento comunicacional, por meio do qual se origina, assume demasiada importância na sua urdidura e manifestação $(2014$, p. 27).

Assim como na poesia oral, comentada acima por Minarelli, a voz cênica voltada à performance e ao teatro também relaciona-se diretamente ao espaço e ao tempo da comunicação. Seu uso deve responder a questões relativas ao que se quer comunicar, com que fim e por que motivo, de modo a ser passível de um processo de investigação consciente. Nesse sentido, a metodologia do Alfabeto do Corpo criada por Zygmunt Molik revela-se uma possibilidade técnica de se trabalhar a qualidade vocal cênica.

${ }^{4}$ Zygmunt Molik (1930-2010) "foi cofundador, ator principal essencial para a formação do treinamento de voz iniciado 


\section{Para além do cotidiano vocal: o Alfabeto do Corpo como uma possibilidade de conexão entre corpo e voz}

No ano de 2012, o curso de Tecnologia em Produção Cênica da Universidade Federal do Paraná - UFPR promoveu o I Seminário de Produção Cênica. Na programação constava a oficina intitulada Do corpo e da voz à composição cinética ministrada por Tiago Porteiro, da Universidade de Évora, e Jorge Parente, ator responsável pela transmissão do trabalho desenvolvido por Zygmunt Molik ${ }^{4}$.

A oficina oportunizou aos participantes a experimentação de parte da metodologia desenvolvida por Molik que, segundo explicações de Giuliano Campo "têm como foco a libertação da energia criativa e a busca da conexão entre corpo e voz como base para o processo do ator." (Campo e Molik, 2012, p. 5). Batizada de Alfabeto do Corpo, essa metodologia apresenta, conforme já mencionado, um processo técnico no qual corpo e voz estão integrados. Para Campo, Molik.

Desenvolveu o alfabeto como uma ferramenta para o trabalho sobre si mesmo, junto com seu uso pragmático no treinamento do ator. Então, mesmo depois da dissolução da companhia, em 1984, Molik continuou utilizando essa ferramenta durante suas sessões. O trabalho de Voz e Corpo permitiu a Molik conhecer e ensinar milhares de praticantes em todo o mundo durante mais de trinta anos (Ibidem, p. 20).

O criador do Alfabeto do Corpo concedeu a Jorge Parente a autorização para disseminar seu método na condição de seu sucessor. Em entrevista concedida a Giuliano Campo, relatou: "O problema das minhas oficinas é que não tem ninguém para dar continuidade ao trabalho, com exceção de Jorge Parente, de Portugal, que mora em Paris. Ele será meu sucessor, pois domina tudo com precisão" (Ibidem, p. 119).

Esse método, enriquecido pelas novidades que naturalmente trouxeram o processo de sucessão de seu criador, bem como pelo intenso intercâmbio de seus idealizadores com teóricos e artistas em diferentes partes do mundo, incorpora-se por isso na presente reflexão sobre o hibridismo cultural. Resulta profícuo examinar como esse método vem sendo apropriado pelas diferentes pessoas que o experimentaram nas oficinas ofertadas por Jorge Parente, bem como, a partir daí, que novos significados eventualmente têm se acrescido ao método como resultados das diversas apropriações de que é alvo.

Em relação à experiência observada na oficina ocorrida na UFPR, pudemos constatar que, embora a execução dos exercícios propostos tenha sido relativamente simples, apta a ser vivenciada pelos participantes, o mesmo não se verificou em relação à qualidade técnica desejada na experimentação. A aparente simplicidade conferida às chamadas letras do alfabeto, que representavam cada qual uma ação corporal específica, por vezes levou o intérprete a uma reprodução em que faltava a intensidade e a energia esperadas em cada ação. Conforme afirmou o próprio Molik sobre o seu método: "no 'Alfabeto do Corpo', tudo é para pessoas normais" (Ibidem, p. 126). "Talvez não com muita qualidade, mas todos são capazes de fazer" (Ibidem, p. 127).

Composto por aproximadamente trinta ações, a partir das quais é possível construir um tipo de linguagem corporal pautada em um desenho preciso, na metodologia 
do Alfabeto do Corpo nada é mecânico e todos os exercícios são feitos para servir à voz.

No caso da experiência em Curitiba, apenas sete participantes realizaram a oficina, o que oportunizou um sofisticado e detalhado cuidado no processo de aplicação e expe rimentação do método, culminando em uma notável e significativa alteração vocal produzida durante e após a vivência do Alfabeto do Corpo.

Jorge Parente e Tiago Porteiro acompanharam atentamente a investigação de cada participante: desde a repetição dos movimentos, a conexão com a respiração, o investimento técnico na pronúncia do som "Ohh", o desequilíbrio provocado no corpo em sintonia com a sustentação vocal, a prática do canto e de jogos vocais, até a possibilidade concreta de chegarem, gradativamente, à chamada "abertura da voz", na qual a alteração da voz cotidiana para a voz cênica se tornou perceptível.

Ao grupo ainda foram transmitidas algumas letras do Alfabeto do Corpo, suficientes para a construção de partituras corporais que possibilitassem improvisações individuais e coletivas onde voz e corpo eram trabalhados simultaneamente. A pesquisa de sonorização com palavras, frases curtas, textos e canto ocorria simultaneamente aos exercícios técnicos, o que garantia uma projeção e clareza vocal de grande qualidade. Tudo isso foi pautado na busca da energia adequada para cada gesto e som produzido.

A disseminação da metodologia do Alfabeto do Corpo por Parente permite que diferentes artistas redescubram outras formas de ampliar a capacidade vocal e possam vivenciar momentos semelhantes aos que ele descreve ter vivido ao longo de sua convivência com Molik. Segundo seu relato publicado na apresentação da obra organizada por Giuliano Campo:

Testemunhei momentos únicos de doação e compartilhamento, de expressão de si, de uma qualidade de ser, no aqui e agora, ressoando com o outro, com nossas lembranças. Quando uma voz se abria, ela se tornava visível para nós; nossos olhos e nossa atenção eram modificados ali, instantaneamente. Zygmunt Molik acompanhou minha busca com um olhar atento, orientou-me sempre com sugestões, guiou-me. Aos poucos, ele me iniciou na transmissão. Em primeiro lugar, solicitando-me progressivamente, com serenidade e paciência, com humor e leveza, pedindo-me para mostrar um elemento ou outro do Alfabeto do Corpo; depois, para ocupar o lugar de líder no trabalho de grupo. Ele despertou meu sentido de observação e escuta, fez com que eu tomasse consciência da importância da linguagem apropriada para cada intervenção e, só depois, convidou-me a intervir no trabalho de realização vocal (Ibidem, p. 10).

O relato de Parente evidencia a dedicação e o investimento teórico e prático que naturalmente requer o processo de apropriação de um saber, de uma linguagem específica, apropriação que ocorre de maneira gradativa e dinâmica. $O$ trabalho com - Alfabeto do Corpo pode ser entendido como a ampliação do sentido de observação e escuta. Encontrar a voz através da escuta está relacionado a ouvir a si mesmo, aos outros e aos sons que nos rodeiam.

\section{Entre a experimentação acadêmica e o palco na redescoberta da voz}

Este último tópico pretende apresentar o relato de duas experiências distintas em relação ao trabalho com a voz. O primeiro diz respeito ao processo de busca da voz cênica de Bruna Michelin que, além de designer, vem desenvolvendo pesquisas 
artísticas como cantora. O segundo retrata brevemente a experiência docente da relação entre corpo e voz vivida por essa autora.

Convidada para descrever sua experiência, Michelin colaborou com uma espécie de memorial que será aqui transcrito conforme elaborado por ela:

Em meus primeiros anos de vida, me chamava atenção o jeito como as pessoas falavam: sotaques, pronúncia das palavras, velocidade da fala, características estas que, muitas vezes, se distanciavam da minha forma de falar. Costumava ouvir e imitar essas características.

Talvez pelo fato de terem pais de estados diferentes, minha mãe do litoral de Santa Catarina e meu pai do interior do Estado do Paraná, minha audição foi aguçada pela diversidade sonora e pelo hibridismo vocal que eram produzidos no âmbito familiar. Entendo esta fase de apropriação e imitação de sotaques e de "jeitos de falar" como uma primeira prática, de certa forma inconsciente, do uso da voz. Observava falas de pessoas provenientes de diferentes locais, de sexos e idades diversos. Exercitava o ouvir, tentando, a partir de uma brincadeira, identificar o caminho percorrido pelo ar até se transformar em som. Depois, traduzia e recriava esse som em meu próprio corpo, tentando reproduzir ao máximo o som que tinha ouvido. O que permitia uma descoberta de novas possibilidades na elaboração da fala, da projeção do som dentro da boca, da pronúncia das palavras e do ritmo na construção de uma frase.

Essa 'brincadeira descomprometida' era aplicada constantemente, não só na tentativa de reproduzir as falas, mas também às vozes cantadas das músicas às quais estava exposta em meu cotidiano. $\mathrm{O}$ objetivo era sempre chegar o mais próximo possível do som emitido pelo artista e entender como aquele som passava pelo corpo para adquirir determinada característica. E isso me levou à observação da projeção da voz em diferentes idiomas. Do português, por ser minha língua natal, passei para o inglês, em uma tentativa mais ousada, visto que ainda não tinha estudado esta língua. Ainda criança fui submetida a uma cirurgia de nódulos nas pregas vocais o que me levou a perceber a necessidade de cuidados que deveria ter com a voz, seja em relação a abusos vocais, na forma hereditária de conduzir a fala ou ainda na percepção de que voz e corpo são expressões indissociáveis. O canto, de brincadeira caseira, passou a tornar-se algo mais significativo em minha vida.

A busca por um maior entendimento da minha voz se iniciou simultaneamente aos meus estudos teatrais, quando realizei as oficinas Do Corpo ao Canto, coordenado por Edith de Camargo; o Corpo Lúdico, por Rossella Terranova e o Ator Criador, por Luis Melo, ofertadas pelo Ateliê de Criação Teatral em 2007, na cidade de Curitiba. Essas oficinas foram o estopim para o despertar de minha consciência corporal de maneira mais significativa. A primeira oficina tinha uma relação direta com a voz, na qual desenvolvíamos exercícios vocais que envolviam o preenchimento do espaço com o som, a movimentação do corpo nesse espaço cantado, a projeção vocal e um estudo inicial da fisiologia da voz, focado nas partes do corpo que tinham envolvimento direto com os exercícios propostos. As outras oficinas pensavam o corpo colocando em prática uma série de exercícios que misturavam o uso da voz com a movimentação corporal, a exploração das emoções e a resposta do corpo a estímulos musicais.

No ano de 2009, ao ingressar na banda Janela Oval, investiguei diferentes estilos musicais. Da MPB ao Rock dos anos 60 e 70, na língua inglesa e na portuguesa, tentando observar nos diferentes estilos, em quais me sentia mais confortável e, novamente, atenta às limitações e extensões da minha fisiologia vocal. Mais tarde criei, em parceria com os músicos Ivan Roccon e Mateus Castella, a banda Hot Beigal Shop, que trabalha na composição de diferentes estilos musicais em inglês, português e francês.

O objetivo é explorar a diversidade sonora das línguas (pronúncia das palavras, projeção da voz e métrica), "brincar" com a dificuldade de se fazer entender em uma língua que não é a sua de origem (intenção dos discursos, significados varia-

\footnotetext{
${ }^{5}$ Por Bruna Michelin em junho de 2014.
} 
dos e expressões idiomáticas) e de encaixá-la em um estilo musical para o qual não foi prevista, por exemplo cantar bossa em francês.

Outro projeto de qual faço parte é a banda Six Pack Squad, que interpreta composições dos anos 40 e 50 e que me permite buscar nas vozes de intérpretes do Jazz, do Blues e do Soul minhas maiores referências sonoras. Nesse projeto, surge um novo desafio: a apresentação em variados espaços, como em bares, praças, eventos e festivais. Essa diversidade espacial ao alterar a propagação do som agrega à minha experiência a necessidade de encontrar uma projeção vocal correspondente às exigências locais e que permita um 'encontro' com o público.

Em 2011 retomei meus estudos vocais com a professora Adriana Fabro de forma mais aprofundada. Investigamos a fisiologia da voz, a prática da respiração, os exercícios de aquecimento e "desaquecimento", o uso da técnica vocal pautada na sustentação do ar no diafragma e a intenção do canto, que se evidencia de uma forma ou de outra de acordo com o tipo de projeção vocal. As experiências aqui relatadas não encerram a busca de novos investimentos relativos à pesquisa vocal. Na medida em que vivencio novas experiências, percebo o quanto esse processo de busca é permanente ${ }^{5}$.

A experiência descrita por Michelin aponta para questões discutidas anteriormente em relação à escuta como possibilidade de um "encontro vocal" singular, ainda que em relação a aspectos sociais e culturais conectados à experiência. A busca da voz por um processo de investigação híbrida pode ser observada nos investimentos realizados por ela no canto, no teatro e nas relações cotidianas que, somados à necessidade de um maior cuidado com a voz em decorrência de nódulos vocais, chamam a atenção para o fato de que um intercâmbio entre as áreas do canto, da fonoaudiologia e do teatro permite proporcionar uma maior consciência no uso da voz cênica.

Na sequência, será apresentado um breve relato da autora sobre sua experiência docente. No ano de 2009, iniciei minhas atividades docentes no Curso Superior de Tecnologia em Produção Cênica da UFPR depois de onze anos à frente da disciplina de Expressão Corporal dos cursos de Teatro (Licenciatura e Bacharelado) da Faculdade de Artes do Paraná -FAP.

O ingresso na UFPR trouxe o desafio de também trabalhar com questões relacionadas à voz. A partir de então iniciei investimentos teóricos e práticos nesta área. Como docente da disciplina de Linguagens do Corpo e da Voz, venho desenvolvendo pesquisas que possibilitem a ampliação da minha percepção em relação à conexão corpo e voz, bem como à construção de uma metodologia de trabalho apropriada para um grupo discente bastante heterogêneo, o que permite relacionar meus estudos com o processo de hibridação cultural discutido no início deste artigo.

De maneira geral, minha interlocução teórica abrange os autores trabalhados neste texto, além de investimentos práticos a que venho me submetendo deste então. Entre as diversas oficinas realizadas, destaco o curso ofertado por Jorge Parente em Curitiba e já mencionado precedentemente; oficina com o Grupo Lume, voltadas para a voz, e com o Corpo Musical dirigidas por Jean-Jacques Lemêtre. Esses investimentos somam-se a um estudo voltado para as questões anatômicas e fisiológicas da voz, que desenvolvi no curso de Fonoaudiologia da Universidade Tuiuti do Paraná. Além disso, aulas de canto solo foram feitas visando compreender e, de certa forma, redescobrir a minha própria voz em conexão com o meu corpo.

Em relação à disciplina Linguagens do Corpo e da Voz, ela vem sendo construída e repensada a cada ano em que é ofertada. Parto da convicção de que corpo e 
voz, indissociados, são formadores de expressões construídas culturalmente, e que, portanto, demandam reflexão crítica e novas vivências para além dos automatismos cotidianos. A partir desta premissa, as aulas são organizadas em três eixos metodológicos: reflexão teórica, vivência prática e ampliação de repertório artístico voltado para as artes cênicas.

De maneira geral, contatos introdutórios com a ideia de voz performática, com a observação crítica da paisagem sonora, com os princípios de trabalho inspirados em Eugênio Barba, com o Alfabeto do Corpo, traduzem, em uma perspectiva híbrida, questões que permeiam a prática docente. Por fim, o trabalho tem por objetivo oportunizar aos estudantes possibilidades de pesquisa que permitam aprofundar a percepção de que a performance vocal é algo que se constrói conscientemente por meio de processos dinâmicos, transitórios e, por vezes contraditórios, em virtude dos aspectos históricos e sociais inerentes a eles.

\section{Considerações Finais}

O caminho percorrido no presente artigo sugere a perspectiva cultural e híbrida como possibilidade de pensar a performance vocal, seja em cena voltada a diferentes públicos e em espaços variados, seja em laboratórios experimentais em sala de aula, na qual o exercício da escuta deve se fazer sempre presente.

A voz compreendida como um processo cultural proporciona processos mais conscientes de investigação sonora que, em conexão com o corpo, revela processos híbridos construídos culturalmente.

O diálogo com diferentes teóricos possibilita, por meio do intercâmbio de suas teorias, o desenvolvimento de metodologias híbridas de pensar e de trabalhar a relação entre corpo e voz.

Os sentidos de observação e de escuta fazem parte do processo de encontro da voz performática, distanciada do aspecto mecânico e automatizado da comunicação cotidiana.

\section{Referências}

BARBA, Eugênio. A Canoa de Papel: Tratado de Antropologia Teatral. Brasília: Dulcina, 2012.

BURKE, Peter. Hibridismo Cultural. São Leopoldo: Unisinos, 2003.

CAMPO, Giuliano; MOLIK, Zygmunt. Trabalho de Voz e Corpo de Zygmunt Molik: O Legado de Jerzy Grotowski. São Paulo: Realizações Editora, 2012.

LEHMANN, Hans-Thies. Teatro Pós-Dramático. São Paulo: Cosac Naif, 2007.

MINARELLI, Enzo. As Razões da Voz: Entrevistas com Protagonistas da Poesia Sonora no Século XX/Enzo Minarelli, Frederico Fernandes. Londrina: Eduel, 2014. SCHAFER, Raymond Murray. A Afinação do Mundo. São Paulo: Unesp, 2011. 
ZUMTHOR, Paul. A Letra e a Voz: a "Literatura" Medieval. São Paulo: Companhia das Letras, 1993.

Performance, Recepção e Leitura. São Paulo: Cosac Naif, 2007.

TATIT, Luiz. O Século da Canção. São Paulo: Ateliê Editorial, 2008.

Recebido em 12/05/2014 Aprovado em 09/07/2014 